\title{
Impaired macrophage autophagy induces systemic insulin resistance in obesity
}

\author{
Young-Ho Kang1,3, Mi-Hyang Cho ${ }^{2,3}$, Ji-Young Kim ${ }^{1,3}$, Min-Seo Kwon ${ }^{1,3}$, Jong-Jin \\ Peak $^{2,3}$, Sang-Wook Kang ${ }^{1,3}$, Seung-Yong Yoon ${ }^{2,3, *}$ and Youngsup Song ${ }^{1,3, *}$ \\ ${ }^{1}$ Department of Biomedical Sciences, University of Ulsan College of Medicine, Asan Institute for Life Sciences, Asan Medical \\ Center, Seoul, Korea \\ ${ }^{2}$ Alzheimer's Disease Experts Laboratory (ADEL), Department of Brain Science University of Ulsan College of Medicine, Asan \\ Institute for Life Sciences, Asan Medical Center, Seoul, Korea \\ ${ }^{3}$ Bio-Medical Institute of Technology (BMIT), University of Ulsan, College of Medicine, Seoul, Korea \\ * These authors have contributed equally to this work \\ Correspondence to: Youngsup Song, email: ysong@amc.seoul.kr \\ Seung-Yong Yoon, email: ysy@amc.seoul.kr
}

Keywords: autophagy, adipose tissue macrophage, insulin resistance, obesity, reactive oxygen species, Pathology Section

Received: February 23, 2016

Accepted: May 20, 2016

Published: May 25, 2016

\section{ABSTRACT}

Obesity-induced insulin resistance and diabetes are significantly associated with infiltrates of inflammatory cells in adipose tissue. Previous studies recognized the involvement of autophagy in the regulation of metabolism in multiple tissues, including $\beta$-cells, hepatocytes, myocytes, and adipocytes. However, despite the importance of macrophages in obesity-induced insulin resistance, the role of macrophage autophagy in regulating insulin sensitivity is seldom addressed. In the present study, we show that macrophage autophagy is important for the regulation of systemic insulin sensitivity. We found that macrophage autophagy is downregulated by both acute and chronic inflammatory stimuli, and blockade of autophagy significantly increased accumulation of reactive oxygen species (ROS) in macrophages. Macrophagespecific Atg7 knockout mice displayed a shift in the proportion to pro-inflammatory M1 macrophages and impairment of insulin sensitivity and glucose homeostasis under high-fat diet conditions. Furthermore, inhibition of ROS in macrophages with antioxidant recovered adipocyte insulin sensitivity. Our results provide evidence of the underlying mechanism of how macrophage autophagy regulates inflammation and insulin sensitivity. We anticipate our findings will serve as a basis for development of therapeutics for inflammatory diseases, including diabetes.

\section{INTRODUCTION}

Type 2 diabetes mellitus caused by insulin resistance combined with $\beta$-cell dysfunction is a complex metabolic disorder highly associated with cardiovascular diseases, blindness, and renal failure. Insulin resistance appears to be induced mainly by obesity, as approximately $85 \%$ of type 2 diabetes patients are obese [1]. Obesity is characterized by chronic low-grade inflammation and increased infiltration of proinflammatory (M1-like) macrophages into adipose tissue [2, 3]. Macrophages are a major source of inflammatory mediators such as interleukin-1 $\beta$ (IL1 $\beta$ ), interleukin-6 (IL6), and TNF $\alpha$ [24]. Increasing evidence suggests a central role for adipose tissue macrophages in obesity-associated systemic insulin resistance [5-7].

Oxidative stress seems to be an important executor of obesity-associated insulin resistance and type 2 diabetes [1, 8-10]. The mitochondria are an important source of cellular reactive oxygen species (ROS). Mitochondrial dysfunction causes ROS accumulation and activates the nucleotide-binding domain, leucine-rich-containing family, pyd domain-containing-3 (NLRP3) inflammasome and caspase-1 [11-15]. Obesity induces mitochondrial dysfunction and accumulation of ROS in humans and mice $[1,16]$. The attenuation of mitochondrial ROS generation in obese mice preserves glucose tolerance and insulin sensitivity [8]. 
Autophagy is an evolutionarily conserved catabolic process that sequesters cytoplasm, including aberrant organelles and macromolecules, into double-membrane vesicles for delivery to lysosomes for degradation and eventual recycling of the macromolecules [17]. Autophagy is involved in the pathogenesis of various human diseases, including metabolic syndromes [18-22]. Several studies have shown that insulin resistance and metabolic syndrome are distinctly influenced by autophagy in various tissues such as adipose tissues, skeletal muscles, pancreas, liver, and brain [23-30]. Autophagy in adipocytes regulates lipid accumulation in the body by controlling its differentiation and determines the balance between white and brown fat [29]. Autophagy in pancreatic $\beta$-cells is important for islet homeostasis and glucose homeostasis [27, 28]. Autophagy deficiency in skeletal muscles protects against insulin resistance via fibroblast growth factor-21 [26]. Autophagy defects in hepatocytes promote obesityinduced endoplasmic reticulum stress and provoke insulin resistance [31].

In macrophages, autophagy has been shown to be involved in controlling inflammation by regulating mitochondria turnover and ROS generation [14, 15]. However, despite the importance of macrophages in obesity and insulin resistance, the role of macrophage autophagy in regulating insulin sensitivity and glucose homeostasis is rarely addressed. In this study, we speculated whether autophagy in macrophages may regulate obesity-induced inflammation and insulin resistance.

\section{RESULTS}

\section{Autophagy is downregulated in macrophages during inflammation}

To study the role of autophagy in macrophages, we speculated whether this process was regulated by inflammatory stimulation. Treating bone-marrow-derived macrophages (BMDMs) derived from C57BL6 mice with lipopolysaccharide (LPS) appears to downregulate the autophagy process as observed by the decreasing LC3-II conversion and increasing the accumulation of p62, a marker of autophagic degradation (Figure 1A) [32]. As a reflection of inflammation status, caspase-1 cleavage increased and correspondingly IL $1 \beta$ secretion also increased (Figure 1A and Supplementary Figure 1A). A decrease in LC3-II conversion and an increase in p62 accumulation and IL $1 \beta$ secretion were similarly observed in LPS-treated Raw264.7 macrophage cells (Figure 1B and Supplementary Figure 1B). Because obesity is characterized by chronic low-grade inflammation, we wondered whether macrophage autophagy is downregulated in chronic inflammation. Peritoneal macrophages from mice fed a $60 \%$ high-fat diet (HFD) also showed downregulation of LC3-II conversion and upregulation of p62 compared with peritoneal macrophages from normal chow-fed mice (Figure 1C).

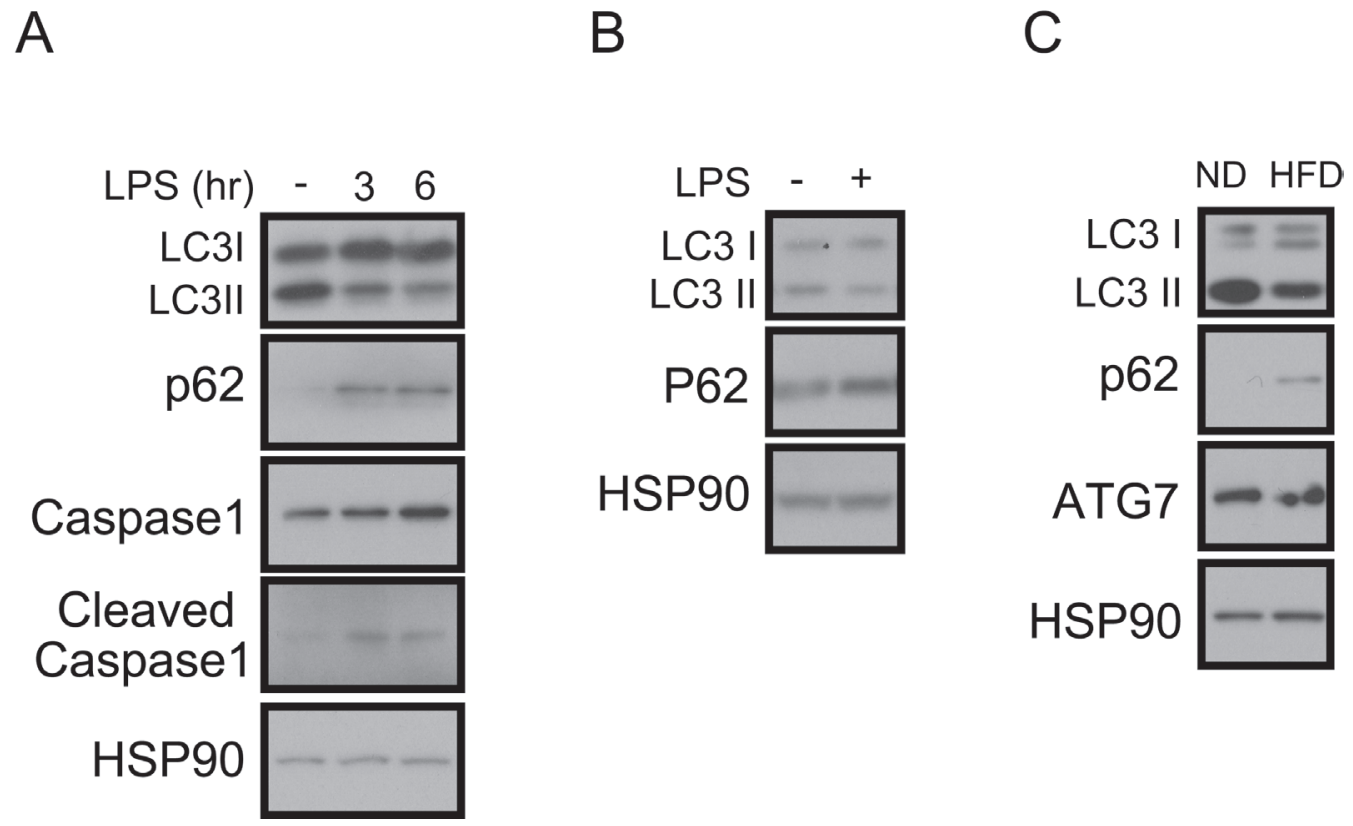

Figure 1: Impaired autophagy and increased IL1ß in LPS-treated macrophages. A. Western blots showing that LC3-II is decreased, p62-sequestosome-1 is increased, and the cleaved form of caspase- 1 is increased in LPS (1 ng/mL)-treated BMDMs from C57BL6 mice. HSP90 was loaded as an internal control. B. Western blots showing that LC3-II is decreased and p62 is increased in the LPStreated Raw264.7 macrophage cell line. C. Western blots showing that LC3-II conversion is decreased and p62 accumulation is increased in peritoneal macrophages from $60 \%$ HFD-fed obese mice compared with macrophages from normal chow diet (ND)-fed mice. 


\section{Generation of macrophage-specific Atg7 knockout mice}

Metabolic syndrome is often linked to chronic inflammation, and because autophagy is downregulated in macrophages by inflammatory stimuli (Figure 1), we wondered whether it plays a role in macrophages and whether there is a link between inflammation and insulin resistance. Accordingly, we generated a macrophagespecific autophagy knockout (KO) system by crossing $\operatorname{Atg} 7^{f / f}$ mice with LysMCre mice (Supplementary Figure 2A). Atg7 expression in BMDMs derived from Atg $7^{A / f}$ - $_{-}$ LysMCre $^{+/-}$mice (referred to as Atg7KO mice hereafter) was decreased in comparison with control BMDMs obtained from LysMCre ${ }^{+/}$mice (referred to as control mice hereafter) by western blot and quantitative real time PCR (qRT-PCR) (Supplementary Figure 2B). As a reflection of the LysM expression in the myeloid lineage, the Atg7 expression levels in the liver and white adipose tissues were comparable, suggesting that the $\operatorname{Atg} 7$ gene is specifically deleted in macrophages by LysMCre expression (Supplementary Figure 2C).

Suppressing autophagy in macrophages is associated with insulin resistance without affecting obesity

At weaning, the Atg7KO mice appeared to weigh slightly more than the control mice, but the weights became comparable between these groups (Supplementary Figure $3 \mathrm{~A}$ ). The circulating glucose level of 5-h and 16-h fasted Atg7KO mice was also comparable to the control group. The glucose tolerance test (GTT) and insulin

A
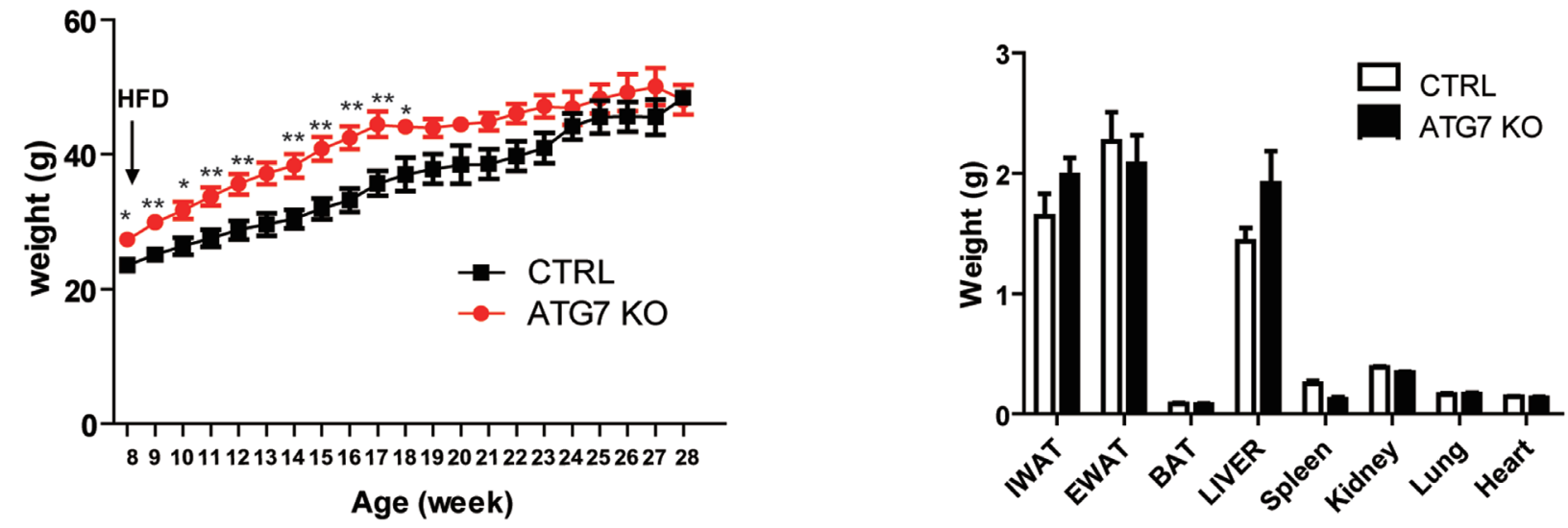

C
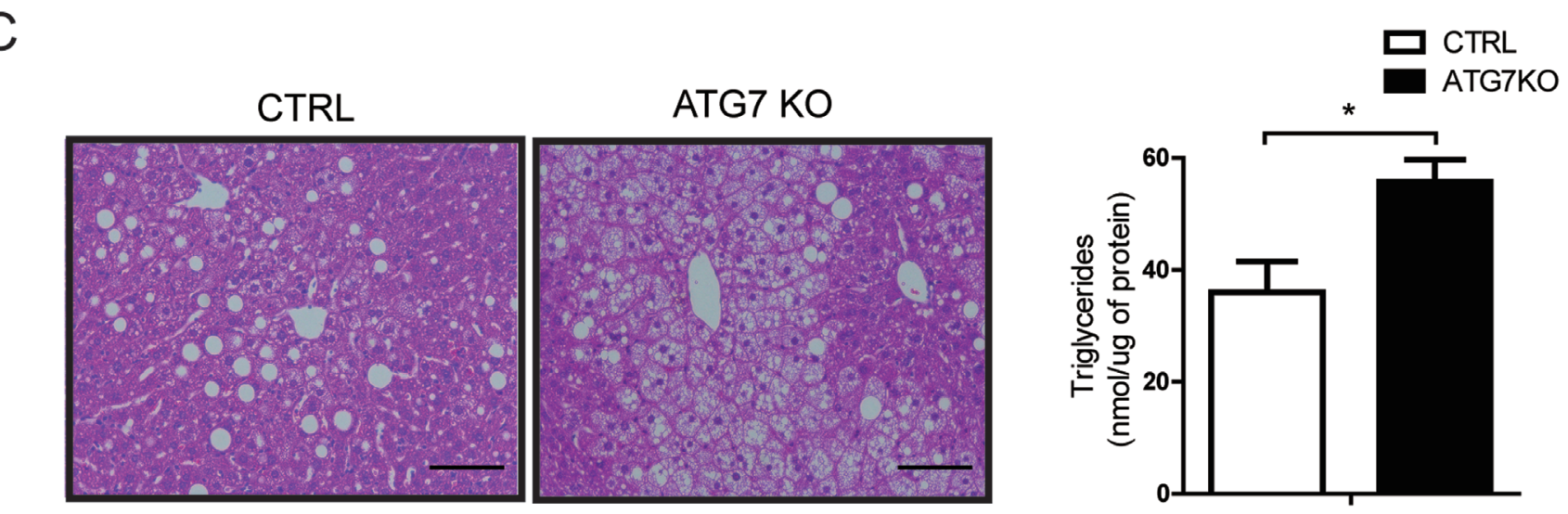

Figure 2: Macrophage-specific Atg7KO mice develop hepatic steatosis under HFD conditions. A. Atg $7^{\text {Af/f }}$-LysMCre ${ }^{+/-}$mice $(\operatorname{Atg} 7 \mathrm{KO})(n=8)$ and LysMCre ${ }^{+-}$mice (control) $(n=6)$ were fed a $60 \%$ HFD, and their growth was monitored by weighing weekly. B. Twenty weeks after administering a $60 \% \mathrm{HFD}$, the tissues from $\operatorname{Atg} 7 \mathrm{KO}(n=8)$ and control mice $(n=6)$ were dissected and weighed. C. Liver sections from Atg7KO and control mice were prepared and stained with hematoxylin and eosin staining. Scale bar, $100 \mu \mathrm{m}$ (left panel). The triglyceride content of liver tissues from control and Atg7KO mice is shown in the right panel. 
tolerance test (ITT) results also suggested that ATG7KO mice had a capability to regulate blood glucose levels comparable to the control mice (Supplementary Figure 3B-3C).

We next challenged the ATG7KO mice with a $60 \%$ HFD. It appeared that the macrophage-specific deletion of the Atg7 gene did not affect obesity. Initially, the HFDfed Atg7KO mice weighed slightly more than the control mice, but the weights became comparable between the groups (Figure 2A). The metabolic cage studies showed that food intake, activity, and energy expenditure were also indistinguishable between the groups (Supplementary Figure 4A-4D). After 20 weeks of HFD feeding, we dissected various organs from the Atg7KO and control mice and measured their weights. Most organs including, the heart, kidney, lungs, and adipose tissue, had comparable weights in the Atg7KO and control groups, but the liver tissue weighed slightly more in the Atg7KO

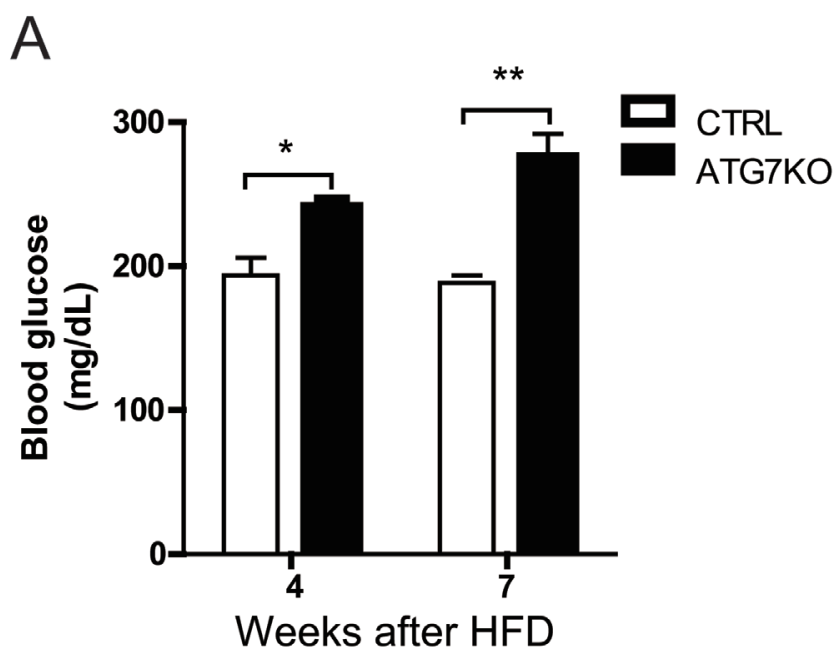

C

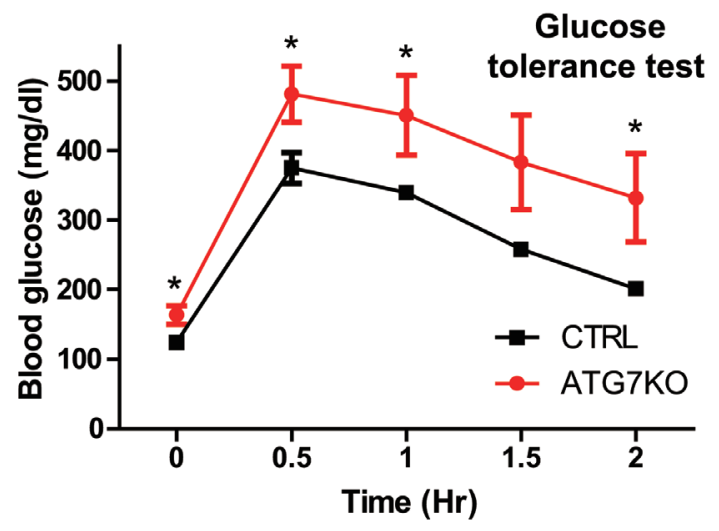

mice (Figure 2B). Interestingly, the liver tissues from the Atg7KO mice showed a severe accumulation of lipids in comparison with the control group (Figure 2C).

One of the major characteristics of insulin resistance is hepatic steatosis. Accordingly, the circulating glucose and insulin levels were found to be higher in Atg7KO mice (Figure 3A-3B), and correspondingly, the Atg7KO mice demonstrated a significantly lower respiratory exchange ratio (Supplementary Figure 4E) and impaired whole-body insulin sensitivity on the GTT and ITT (Figure 3C-3D).

\section{Elevated macrophage infiltration in the adipose tissue of $\operatorname{Atg} 7 \mathrm{KO}$ mice}

Diet-induced obesity increases macrophage infiltration in adipose tissue and contributes to the development of systemic insulin resistance $[2,3,33$,

B

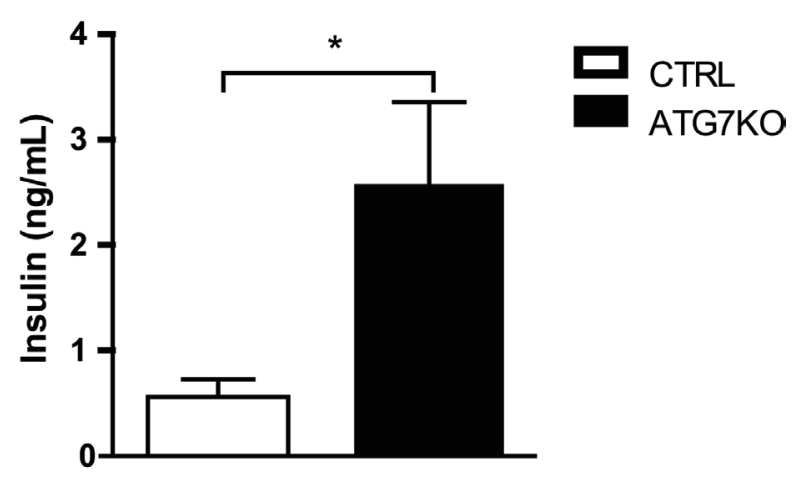

D

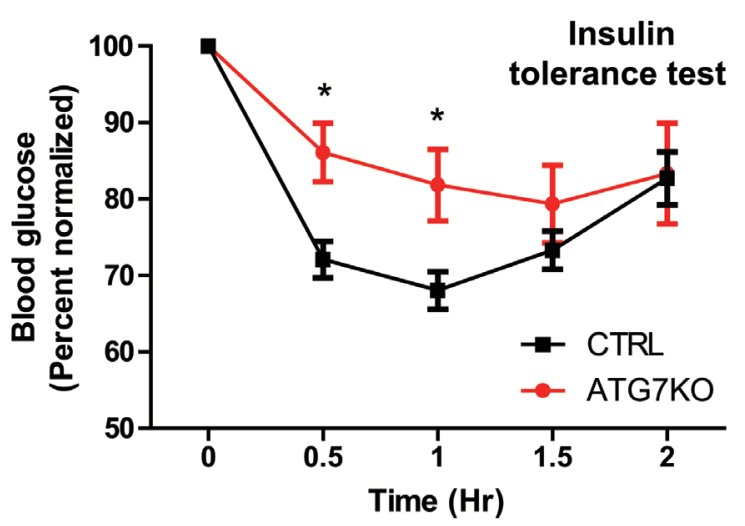

Figure 3: Impaired glucose homeostasis in macrophage-specific Atg7KO mice under diet-induced obesity conditions. A. Circulating blood glucose levels in Atg7KO and control mice during a 60\% HFD challenge. Circulating glucose levels were monitored in 5-h-fasted (weeks 4 and 7 after HFD) mice. B. Circulating insulin levels of $\operatorname{Atg} 7 \mathrm{KO}(n=6)$ and control $(n=6)$ mice were measured using ELISA. C. GTT and D. ITT (right) results for $\operatorname{Atg} 7 \mathrm{KO}(n=8)$ and control $(n=6)$ mice. 
A

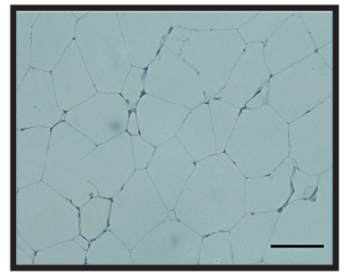

CTRL

B
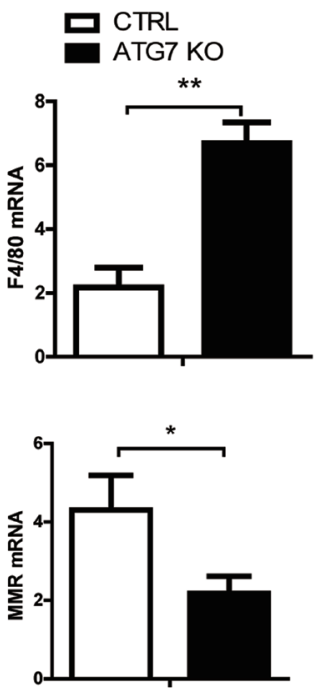

C
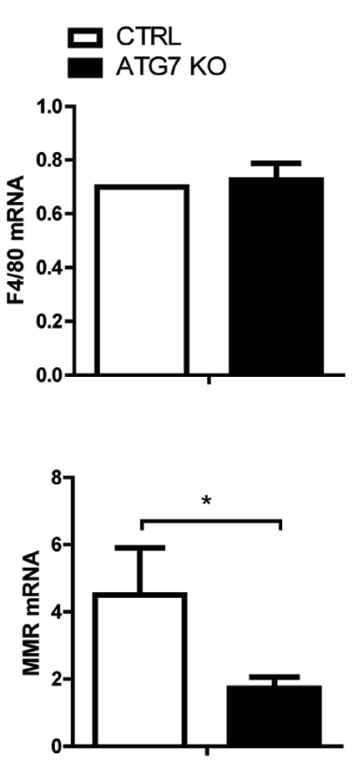

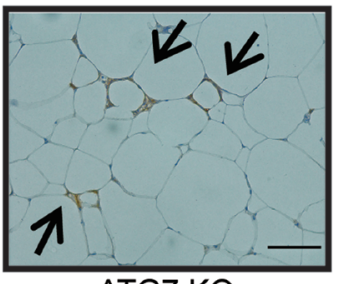

ATG7 KO
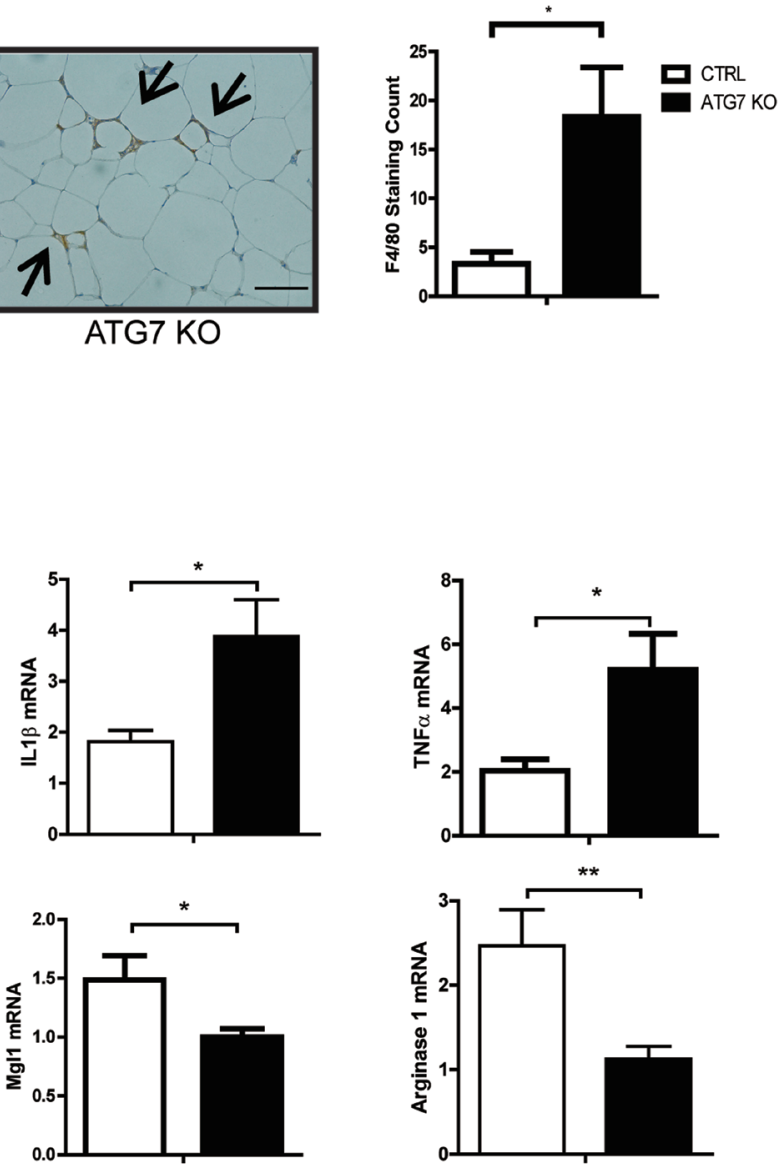
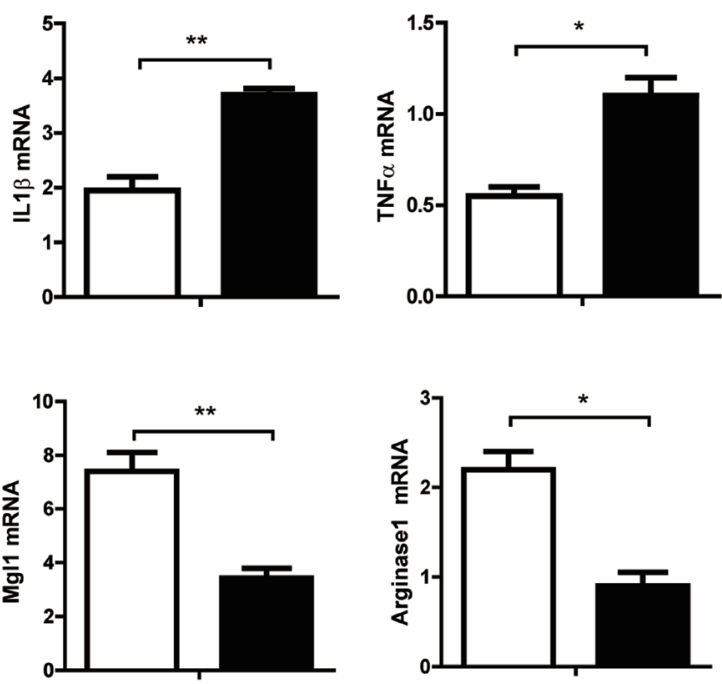

Figure 4: Increased proinflammatory macrophages in the adipose tissue of macrophage-specific Atg7KO mice. A. Immunohistochemistry showing the increased infiltration of F4/80-positive macrophages in the adipose tissues of macrophage-specific Atg7KO mice. B. qPCR analysis showing that the F4/80, IL1 $\beta$, and TNF $\alpha$ mRNA levels increased and the MMR, Mgl1, and arginase 1 mRNA levels decreased in the adipose tissues of Atg7KO mice. C. qPCR analysis showing that IL $1 \beta$ and TNF $\alpha$ transcripts were upregulated and that MMR, Mgl1, and arginase $1 \mathrm{mRNAs}$ were downregulated in the peritoneal macrophages of Atg7KO mice. 
34]. We noticed that both the control and Atg7KO mice in our current study demonstrated increased macrophage accumulation in their adipose tissues, but this was higher in the $\operatorname{Atg} 7 \mathrm{KO}$ mice (Figure 4A). Consistent with the immunostaining results, F4/80 mRNA expression in the adipose tissues of $\mathrm{Atg} 7 \mathrm{KO}$ mice was increased, suggesting the systemic insulin resistance in these mice is associated with increased inflammatory infiltrates in the adipose tissues (Figure 4B). There are at least 2 types of adipose tissue macrophages that have been characterized, and it has been shown that the number of M1 macrophages and the M1/M2 macrophage ratio in adipose tissue are important determining factors for insulin sensitivity. When we analyzed the mRNA expression levels of the M1 and M2 macrophage markers, the M1 markers (including IL1 $\beta$ and TNF $\alpha$ mRNA) increased and the M2 markers (such as MMR, Mgl1, and agrinase1) decreased in the adipose tissue of Atg7KO mice (Figure 4B). Because we saw an increased number of M1 and decreased level of M2 macrophages in the adipose tissue, we hypothesized that autophagy might regulate the M1 and M2 macrophage polarization. To test this, peritoneal macrophages were collected from thioglycolate-injected control and Atg7KO mice, and the M1/M2 population was analyzed using qRTPCR. Similar to adipose tissues, the IL1 $\beta$-expressing and TNF $\alpha$-expressing M1 macrophage population was found to be elevated in peritoneal macrophages from Atg7KO mice, and the M2 population of peritoneal macrophages, expressing MMR, Mgl1, and arginase1 were markedly decreased in Atg7KO mice (Figure 4C).

\section{Blocking autophagy increases ROS in macrophages}

ROS induce inflammation, which in turn activates the NLRP3 inflammasome and interferes with insulin signaling [11]. Blocking autophagy disrupts mitochondrial homeostasis and elevates ROS levels [15, 35]. Accordingly, we found that rotenone treatments increased the ROS level in Raw264.7 cells, and an autophagy block with bafilomycin A1 further enhanced this increase (Figure 5A). It is well established that oxidative stress promotes c-Jun N-terminal kinase (JNK) activation [36, 37]. Consistent with the increase in ROS levels, $\mathrm{CoCl}_{2}$ and rotenone induced the phosphorylation of JNK, and bafilomycin A1 treatment further increased and rapamycin attenuated the cleavage of caspase- 1 and JNK phosphorylation (Figure 5B). To determine whether the ROS level was increased in Atg7KO macrophages, peritoneal macrophages were isolated from Atg7KO and control mice and the ROS level was examined. As shown in Figure 5C and 5D, the ROS level and JNK phosphorylation in peritoneal macrophages were increased by rotenone treatments, and peritoneal macrophages from Atg7KO mice maintained a higher basal ROS level and
JNK phosphorylation in comparison with peritoneal macrophages obtained from control mice. IL1 $\beta$ secretion was correlated with the ROS level. Treatment of Raw264.7 cells with rotenone stimulated IL1 $\beta$ secretion, and the conditioned media obtained from peritoneal macrophages of $\operatorname{Atg} 7 \mathrm{KO}$ mice contained higher levels of IL1 $\beta$ and IL18. These levels were further boosted by rotenone treatment (Supplementary Figure 5A-C). Elevated TNF $\alpha$ mRNA level in peritoneal macrophages from Atg7KO mice (Figure 4C) and increased $\mathrm{TNF} \alpha$ secretion was also observed (Supplementary Figure 5D).

\section{An impaired autophagy process disrupts insulin signaling in adipocytes}

To verify whether insulin resistance is directly caused by impaired autophagy function in macrophages, we first examined insulin signaling in Atg7KO mice. The cleaved form of caspase-1 was increased in the adipose tissue of Atg7KO mice, in which elevated circulating IL1 $\beta$, IL18, and TNF $\alpha$ levels were also observed (Figure 6A-6B). As expected, 16-h fasting downregulated AKT phosphorylation in the white adipose tissue and liver, and 16-h fasting followed by an insulin injection boosted AKT phosphorylation in both groups, however this phosphorylation was markedly attenuated in Atg7KO mice (Figure 6B and Supplementary Figure 6A).

ROS have been shown to stimulate inflammatory cytokine production in macrophages. Because we observed that the ROS level in Atg7KO macrophages increased, we tested whether the secreted cytokines from Atg7KO macrophages were the reason for the insulin resistance in these animals. We collected conditioned media from Raw264.7 cells that were treated with bafilomycin A1 and applied it to 3T3-L1 cells with or without insulin. As shown in Figure 6C, insulin elevated AKT phosphorylation, whereas conditioned media collected from bafilomycin A1-treated Raw264.7 cells inhibited this phosphorylation. Conditioned media collected from Raw264.7 cells that were treated with rotenone also downregulated AKT phosphorylation. Raw264.7 cells treated with bafilomycin A1 and rotenone demonstrated stronger effects, thereby suggesting that an autophagy block plays an additive or additional role in macrophages for the regulation of insulin signaling in 3T3-La preadipocytes and primary hepatocytes (Figure 6D and Supplementary Figure 6B). In accordance with these Raw264.7 data, the conditioned media from the peritoneal macrophages of Atg7KO mice more potently inhibited insulin-mediated AKT phosphorylation in 3T3L1 preadipocytes and primary hepatocytes (Figure 6E and Supplementary Figure 6C).

To further examine the association between macrophage ROS and insulin resistance, we inhibited ROS generation in macrophages by treating with $\mathrm{N}$-acetyl- 
A

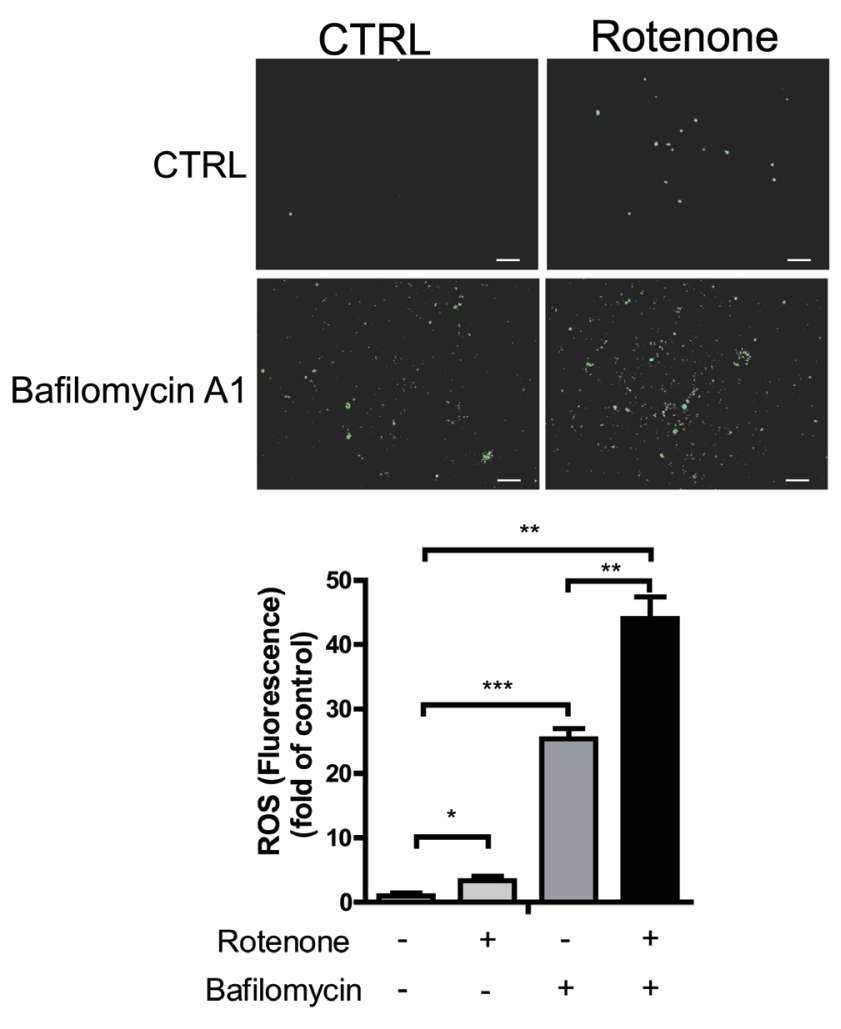

C

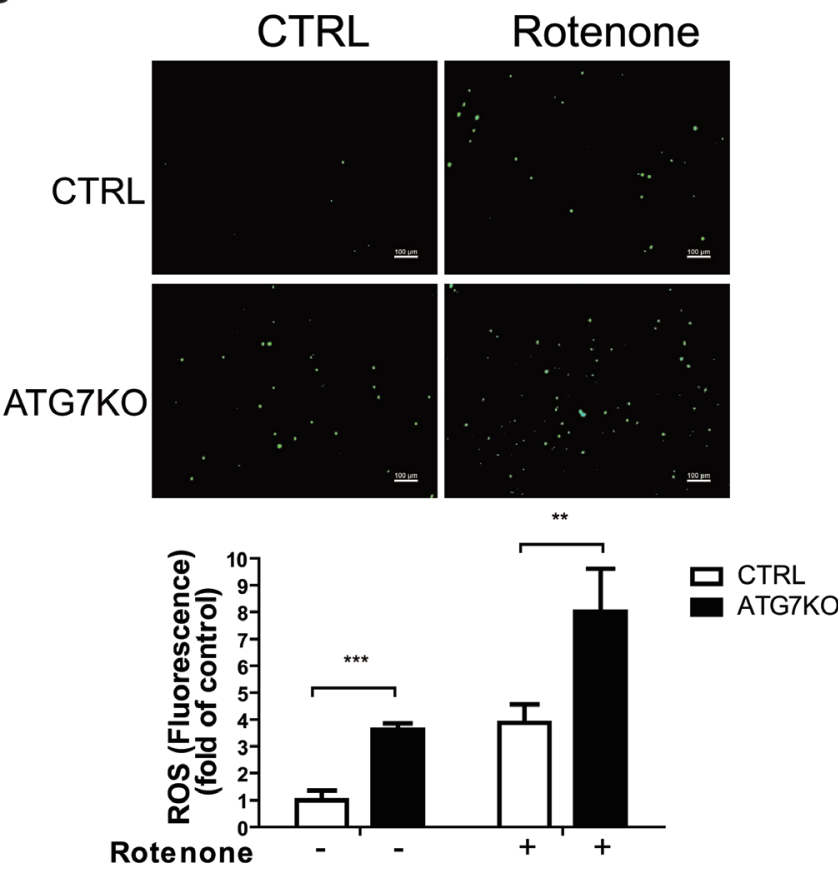

B

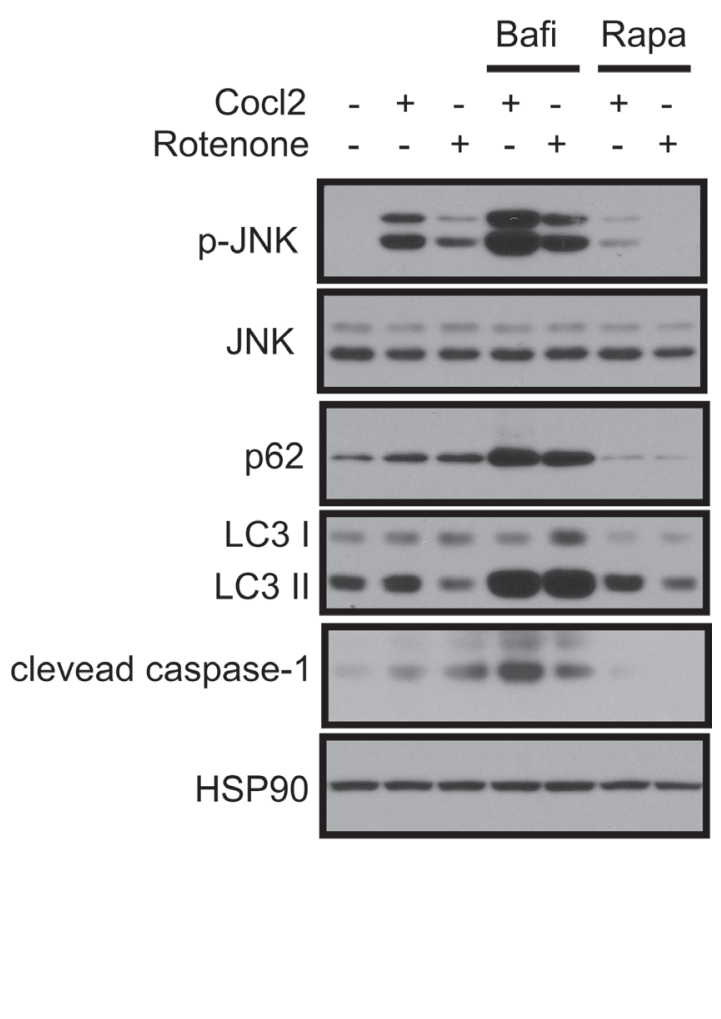

$\mathrm{D}$

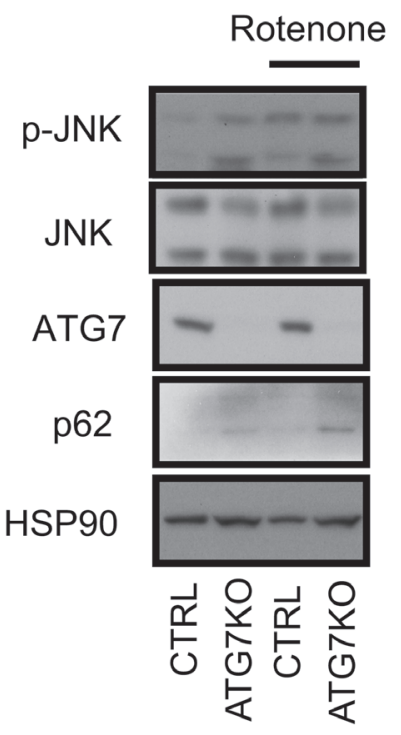

Figure 5: Increased ROS levels in autophagy-impaired macrophages. A. ROS staining of Raw264.7 cells with DCF-DA dye revealed that the ROS levels increased in rotenone-treated or bafilomycin A1-treated cells. B. Western blots showing that phosphorylated JNK (p-JNK) and cleaved caspase-1 levels were increased in $\mathrm{CoCl}_{2}$-treated or rotenone-treated Raw264.7 cells and further increased in bafilomycin A1-treated cells and attenuated by rapamycin treatment. C. ROS staining of peritoneal macrophages with DCF-DA dye showing that the ROS level is increased in the Atg7KO mice and further increased by rotenone treatment. D. Western blots showing that the phosphorylation of JNK is elevated in the peritoneal macrophages of Atg7KO mice. 
A

CTRL

ATG7KO
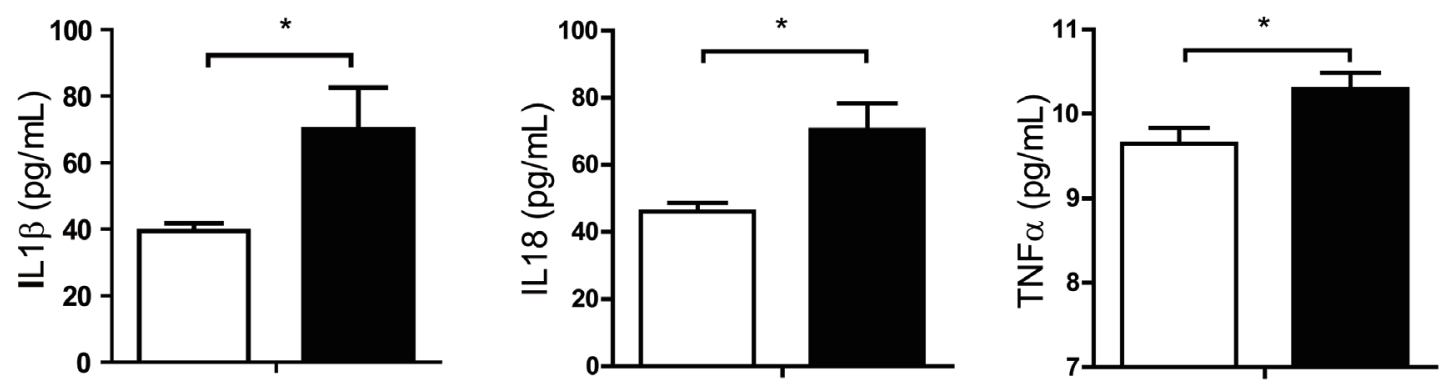

B
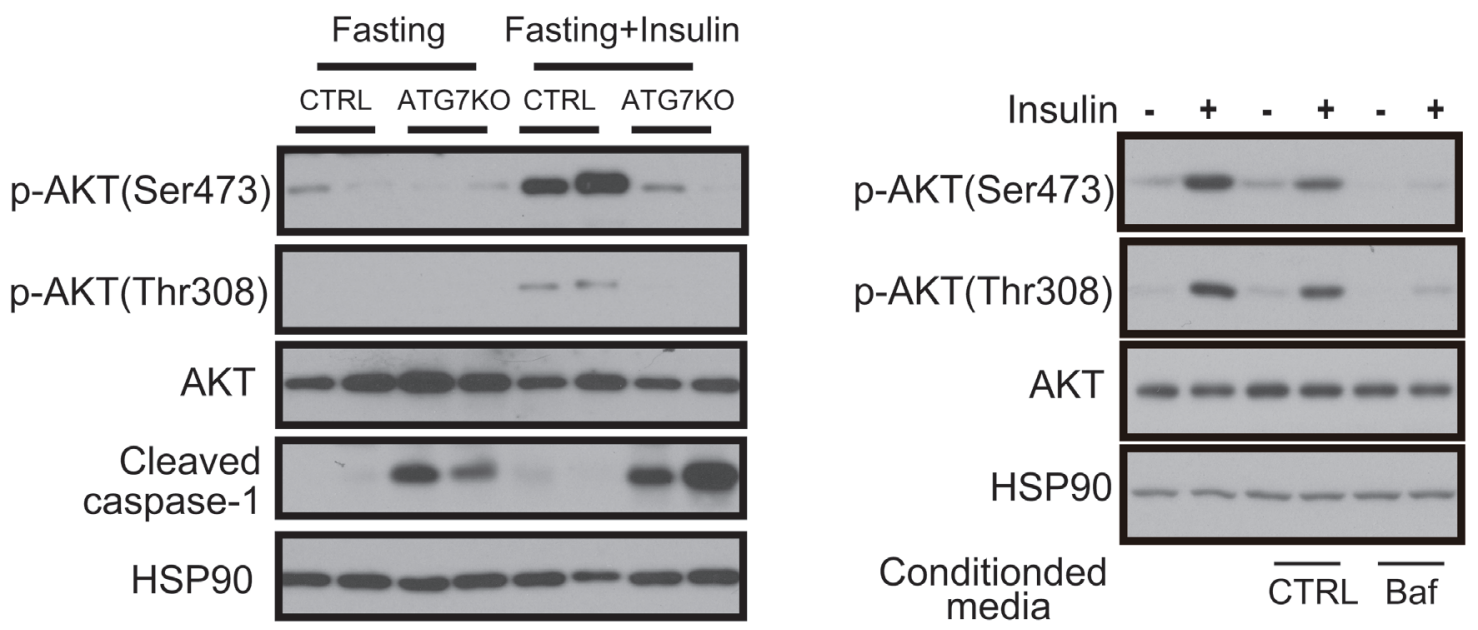

$\mathrm{D}$

E
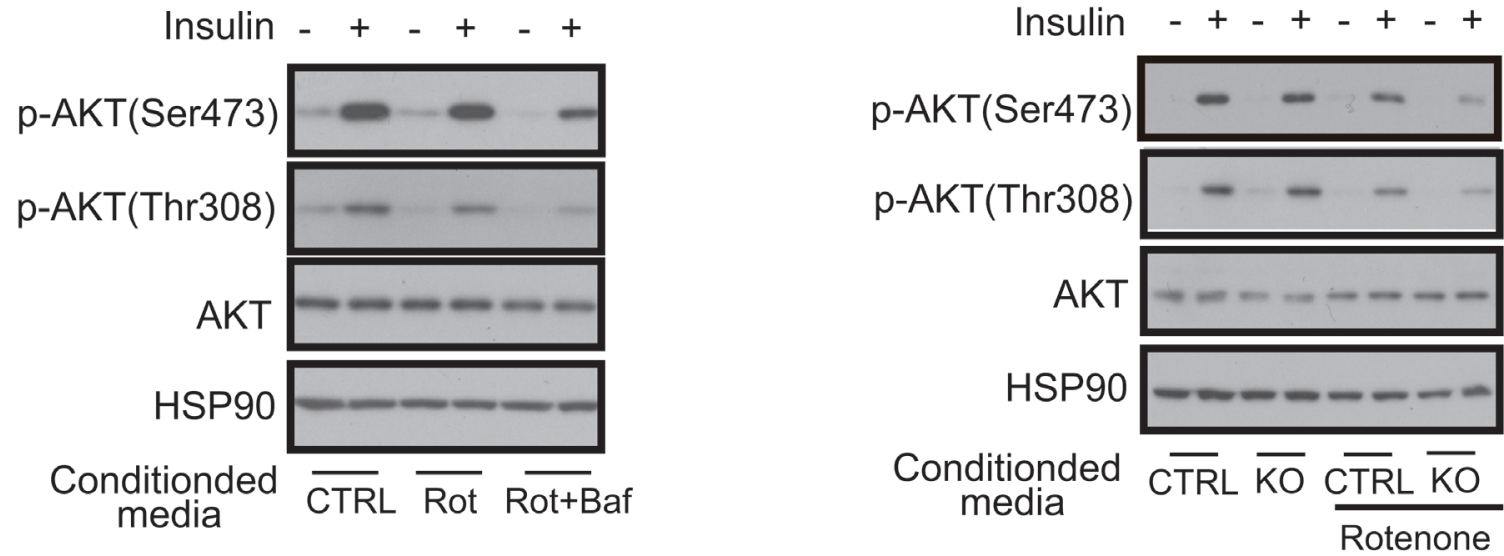

Figure 6: A macrophage autophagy block disrupts insulin signaling in adipose tissues. A. Circulating IL1 $\beta$, IL18, and TNF $\alpha$ levels in Atg7KO ( $n=6-8)$ and control mice $(n=6-7)$ were examined by Elisa. B. White adipose tissue was collected after fasting (with or without insulin injection) from Atg7KO and control mice, and cleaved caspase-1 and insulin signaling were analyzed by western blot. C. Conditioned media collected from Raw264.7 cells treated with bafilomycin A1 and D. conditioned media collected from Raw264.7 cells treated with rotenone (or rotenone and bafilomycinA1) were applied to 3T3-L1 cells with or without insulin, and insulin signaling was then examined by western blot analysis. E. Conditioned media were collected from the peritoneal macrophages of the control and Atg7KO mice and applied to the 3T3-L1 cell line. The insulin signaling pathway was then examined by western blot analysis. 
1-cysteine (NAC). NAC treatments attenuated rotenonemediated ROS generation in peritoneal macrophages derived from both control and Atg7KO mice (Figure 7A). Conditioned media collected from Raw264.7 cells treated with rotenone and NAC recovered insulin-induced phosphorylation of AKT compared with conditioned media collected from Raw264.7 cells treated with only rotenone (Figure 7B). Finally, conditioned media collected from Atg7KO-derived peritoneal macrophages, which were cotreated with rotenone and NAC, also recovered insulin-induced AKT phosphorylation compared with conditioned media treated with only rotenone (Figure 7C).

\section{DISCUSSION}

We show for the first time that macrophage-specific Atg7KO mice exhibit impaired glucose tolerance and insulin sensitivity because of increased M1 macrophages, decreased M2 macrophages, and accumulation of ROS when receiving a HFD. Hence, autophagy in macrophages plays an important role in regulating systemic insulin sensitivity and glucose tolerance.

It appears that autophagy is impaired in chronic obesity. Atg7 is degraded by calcium-dependent protease calpain-2 [38], which is upregulated in an obese liver [31]. Administering a HFD for 16 weeks decreases Atg7 expression in the liver [31]. Chronic lipid exposure also alters the lipid composition of membranes, which decreases the fusion of autophagosomes and lysosomes and thereby results in impaired autophagy [39]. Inflammation is associated with obesity-associated insulin resistance $[5,6]$, and in our current experiments, treating macrophages with inflammatory cytokines impaired autophagy (Figure 1), further supporting the idea that autophagy in macrophages is impaired under obesityinduced inflammatory conditions.

Autophagy in different tissues and cells plays different roles in regulating glucose homeostasis and

A

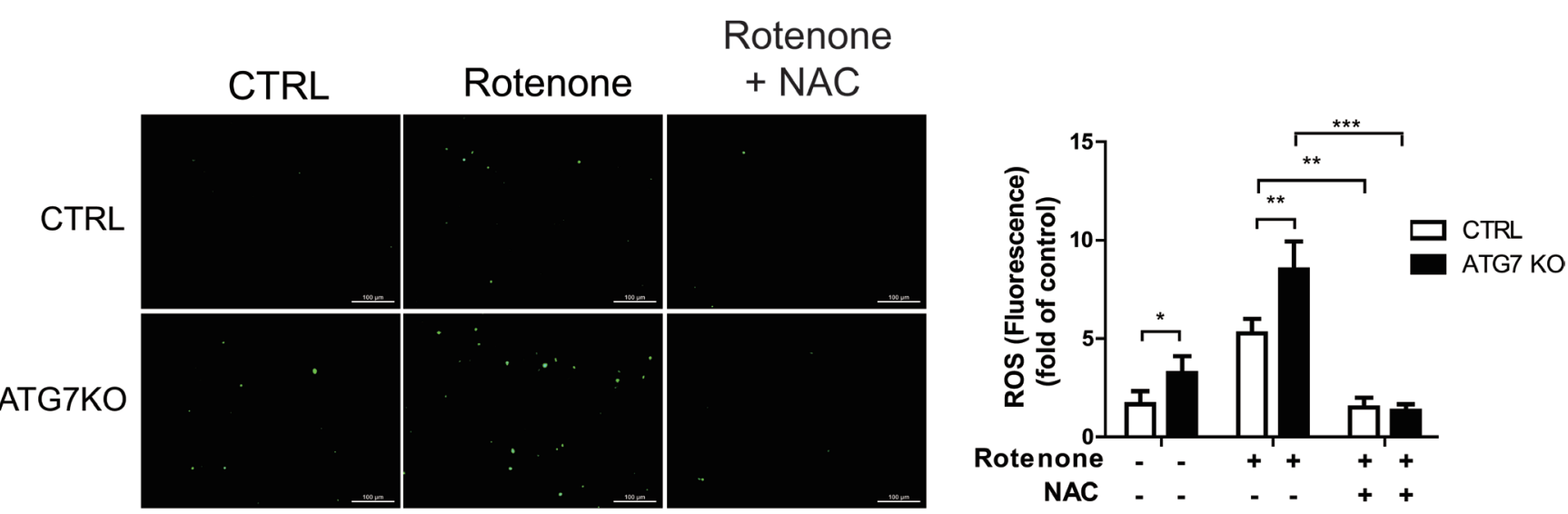

B
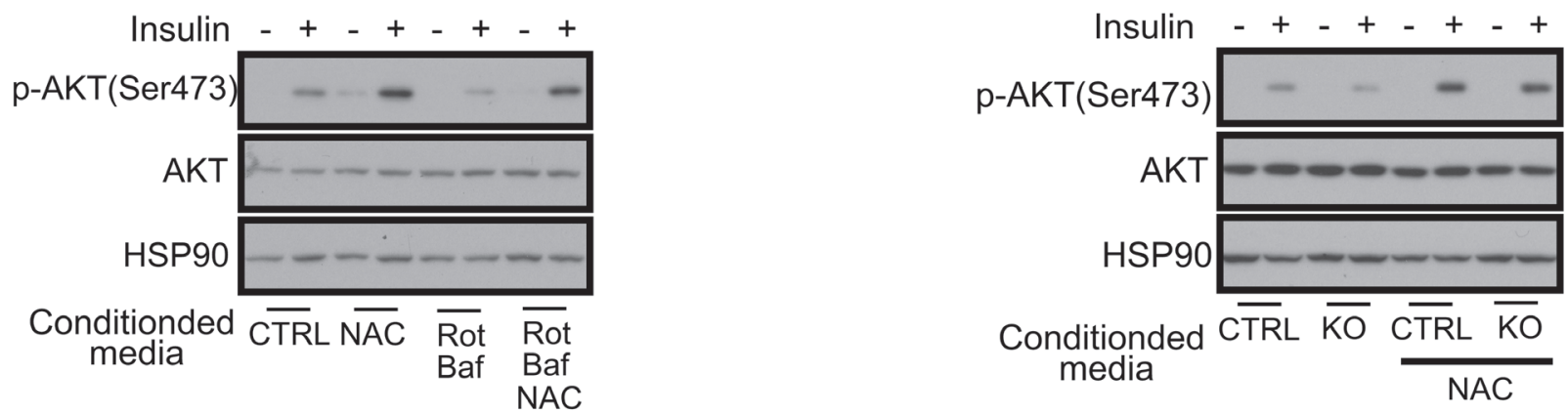

Figure 7: Macrophage ROS are required for the regulation of insulin signaling. A. Peritoneal macrophages from control and Atg7KO mice were treated with rotenone with or without NAC. ROS level measured by DCF-DA staining shows that rotenone-mediated ROS generation is inhibited in peritoneal macrophages from both control and Atg7KO mice. B. Conditioned media were collected from Raw264.7 cells treated with NAC, rotenone, or bafilomycin A1 as indicated and applied to 3T3-L1 cells with or without insulin. Insulin signaling was examined by western blot analysis. C. Conditioned media collected from peritoneal macrophages of control and Atg7KO mice treated with NAC as indicated were applied to 3T3-L1 cells with or without insulin treatment, and insulin signaling was examined by western blot analysis. 
insulin sensitivity. This may be because autophagy has different effects on the characteristics of particular cells [25-29]. Our present study has revealed that autophagy in macrophages plays a significant role in regulating insulin sensitivity and glucose homeostasis (Figures 3 and 6). Insulin signaling is attenuated in the liver and adipose tissues of Atg7KO mice (Figure 6 and Supplementary Figure 6). Insulin signaling in adipocytes and hepatocytes is attenuated after treatment with conditioned media from autophagy-impaired macrophages (Figure 6 and Supplementary Figure 6).

Macrophages are classified as classically activated (M1) or alternatively activated (M2). M1 macrophages arise from stimulation by $\mathrm{T}$ helper type 1 (Th1) cytokines (IFN $\gamma, \mathrm{TNF} \alpha$, and LPS) and secrete proinflammatory cytokines (TNF $\alpha$ and IL1 $\beta / 6 / 12 / 18$ ). M2 macrophages arise from stimulation by $\mathrm{T}$ helper type 2 (Th2) cytokines (IL4/13) and highly express the mannose receptor and secrete various anti-inflammatory molecules (YM1, IL10, and Fizz-1). In atherosclerotic plaques, autophagy-deficient macrophages demonstrate inflammasome activation, increased IL1 $\beta$ production, and the accumulation of cholesterol crystals. Hence, autophagy is necessary for the clearance of cholesterol and the regulation of IL1 $\beta$ production in macrophages by promoting the M2 phenotype [40, 41]. Inhibition of autophagy processes via a lysosomal inhibitor, including chloroquine or bafilomycin A1, results in defects in M2 macrophage polarization [25]. The role of autophagy in regulating the $\mathrm{M} 1 / \mathrm{M} 2$ population under HFD conditions is also supported by a recent report by Liu et al [42]. In this study, macrophage-specific Atg5KO mice demonstrated increased proinflammatory macrophage polarization under HFD conditions in combination with LPS treatment. Our current observation of a higher proportion of $\mathrm{M} 1$ / M2 macrophages in the adipose tissue of Atg7KO mice (Figure 4) also suggests that autophagy in macrophages is important for regulating systemic insulin sensitivity and
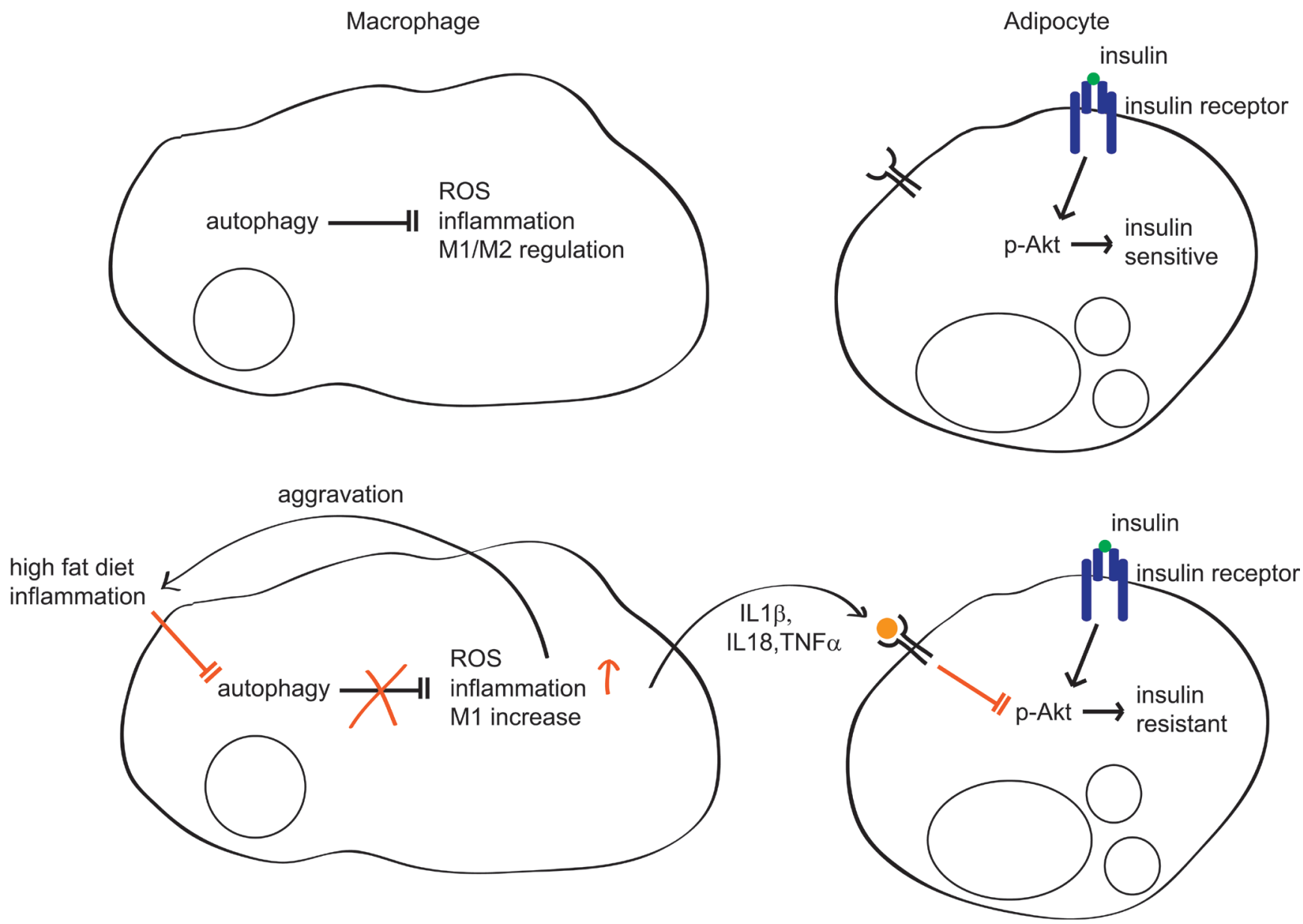

Figure 8: Regulation of insulin sensitivity by autophagy in macrophages. In normal conditions, autophagy regulates inflammation, ROS levels, and M1/M2 populations in macrophages. In this context, adipocytes are sensitive to insulin. However, in inflammatory conditions such as diabetes or HFD, autophagy is impaired in macrophages and its regulation of ROS, inflammation, and the M1/M2 population is also impaired, which further aggravates inflammation and autophagy impairment. Concomitantly, increased inflammatory cytokines such as IL1 $\beta$, IL18, and TNF $\alpha$ inhibit Akt, which impairs insulin signaling, resulting in insulin resistance. 
glucose tolerance by regulating the M1/M2 proportion in obesity.

ROS promote insulin resistance and is associated with obesity and type 2 diabetes mellitus [8-10]. Oxidative stress promotes JNK activation [36, 37]. Obesity-induced insulin resistance and inflammation is aggravated by JNK expression in macrophages [43]. Mitochondrial dysfunction causes ROS accumulation [11] and has been shown to be involved in NLRP3 inflammasome activation [12-15]. Activation of the NLRP3 inflammasome results in the proteolytic cleavage of procaspase- 1 to produce mature caspase- 1 , which cleaves pro-IL1 $\beta$ and pro-IL18 and secretes IL1 $\beta$ and IL18 $[32,44]$. In prediabetes and diabetes conditions, circulating levels of IL1 $\beta$, IL18, and IL1RA, which are induced by IL1 $\beta$, are elevated [19, $45]$, and treatment with IL1 $\beta$ induces insulin resistance in adipocytes, implying that IL $1 \beta$ and IL18 have a crucial role in the development of type 2 diabetes [46]. Autophagy in macrophages is important for preserving mitochondrial integrity regulating ROS generation, and activating NLRP3 inflammasomes [14, 15, 47]. Mitochondria are a rich source of cellular ROS. Elevation of ROS induces autophagy to eliminate damaged mitochondria and suppresses cellular ROS levels. Unsuccessful clearance of damaged mitochondria, for example, by preventing autophagosome formation, increases ROS levels. Our observation of higher ROS and phosphorylated JNK in the macrophages of Atg7KO mice (Figure 5) supports that autophagy in macrophages is important for regulating systemic insulin sensitivity and glucose tolerance via ROS, JNK, and IL1 $\beta$ signaling pathways. In fact, treating type 2 diabetes patients with anakinra, a recombinant IL1R antagonist, decreased inflammation and improved glycemia [18]. Canakinumab, a neutralizing antibody for IL1 $\beta$, is under clinical trial for diabetes $[16,20]$.

Accumulating evidence suggests that oxidative stress along with excessive lipid accumulation in liver, adipose tissue, muscle, and pancreas is the leading cause of insulin resistance. These conditions are induced or exacerbated by overnutrition and are strongly associated with inflammation $[21,22]$. For example, it has been shown that the NLRP3 inflammasome is activated by saturated free fatty acids [48] and is involved in obesity-induced inflammation and insulin resistance [49]. Accordingly, we found that $\mathrm{Atg} 7 \mathrm{KO}$ mice displayed insulin resistance without accompanying body weight changes compared with control mice under HFD conditions. Activation of autophagy by rapamycin or resveratrol or by treating obese mice with apocynin, a ROS blocker, improved glucose homeostasis without weight loss [1, 19-22]. Hence, we hypothesize that autophagy impairment in macrophages may aggravate inflammation and ROS generation, leading to insulin resistance in Atg7KO mice, especially under HFD conditions.

In conclusion, autophagy in macrophages plays a significant role in maintaining insulin sensitivity and glucose homeostasis by regulating macrophage polarization and ROS generation. HFD-induced inflammatory conditions impair autophagy in macrophages, which may provoke production of ROS and proinflammatory M1 cytokines, further aggravating inflammation and autophagy inhibition, resulting in a vicious cycle (Figure 8). We suggest that enhancing macrophage autophagy may be a viable therapeutic or preventative approach to inflammatory disease, including obesity-induced insulin resistance and diabetes.

\section{MATERIALS AND METHODS}

\section{Macrophage-specific Atg7KO mouse model}

Previously described Atg $7^{f / f l}$ mice [50] and LysMCre knockin mice, acquired from The Jackson Laboratory (Bar Harbor, ME, USA), were crossed to produce macrophagespecific $\operatorname{Atg} 7$ conditional $\mathrm{KO}$ mice, i.e., $\operatorname{Atg} 7^{f l / t_{-}}$ LysMCre $^{+/-}$. Deletion of the Atg7 gene was confirmed by genotyping, and its expression was examined by western blot and qRT-PCR. Mice were kept in temperaturecontrolled housing under a 12-h light/12-h dark cycle (lights on at 8:00 AM and off at 8:00 PM) with free access to water and a normal chow diet (Purina Rodent Chow, 38057). For the HFD study, the normal chow diet was switched to a $60 \%$ HFD (Research Diets, D12492) when the mice were 6-8 weeks of age. All animal studies were conducted according to an approved protocol from the Institutional Animal Care and Use Committee of Asan Life Science Institute, Asan Medical Center, Seoul, Korea.

\section{Cell culture and isolation of BMDMs and peritoneal macrophages}

Raw264.7 and 3T3-L1 cell lines were cultured in Dulbecco's minimal essential medium (DMEM) supplemented with 10\% FBS (Hyclone, Logan, UT, USA) and $1 \%$ penicillin/streptomycin. For BMDMs, bone-marrow cells were collected from the femur and tibia of mice and cultured in $\alpha$-MEM supplemented with $10 \%$ FBS and $30 \mathrm{ng} / \mathrm{mL}$ macrophage colonystimulating factor. Unattached cells were removed daily, and fresh culture media was replaced every 3-4 days. For peritoneal macrophage isolation, thioglycolate-stimulated macrophages were collected from $\operatorname{Atg} 7^{f / f l}-\mathrm{LysMCre}^{+/-}$ and control mice by peritoneal lavage 3-4 days after the intraperitoneal injection of sterile $3.85 \%$ thioglycolate. The isolated cells were washed with PBS and plated at a density of 106 cells/mL of DMEM/10\% FBS/penicillin/ streptomycin. The next day, the floating cells were washed away and the attached macrophages were treated and analyzed as indicated. 


\section{Reagents and treatments}

A final concentration of 1-10 $\mathrm{ng} / \mathrm{ml}$ LPS (Sigma Chemical Co., St. Louis, MO, USA), 5- $\mu \mathrm{M}$ rotenone (Tocris, Bristol, UK), 0.5- $\mu \mathrm{M} \mathrm{CoCl}{ }_{2}$ (Sigma), $0.1-\mu \mathrm{M}$ bafilomycin A1 (Tocris), 200-nM rapamycin (Tocris), and $20 \mathrm{mM} \mathrm{NAC} \mathrm{(Sigma)} \mathrm{was} \mathrm{applied} \mathrm{to} \mathrm{the} \mathrm{cells} \mathrm{as}$ indicated in the figures. For the in vivo insulin signaling study, 2-U/kg Humulin (Lilly, Indianapolis, IN, USA) was intraperitoneally injected, and for the in vitro insulin signaling study a final concentration of $50 \mathrm{ng} / \mathrm{mL}$ insulin was administered.

\section{Metabolic cage studies}

Metabolic cage studies were conducted as previously described [51]. Briefly, mice were individually housed for acclimation before the experimental day. $\mathrm{O}_{2}$ consumption, $\mathrm{CO}_{2}$ production, locomotor activity, and food intake were then monitored using an indirect calorimeter (Columbus Instruments, Columbus, OH, USA).

\section{GTT and ITT}

For the GTT, 16-h fasted male mice were intraperitoneally injected with glucose $(1.5-2 \mathrm{~g} / \mathrm{kg}$ depending on the weight of mice), and glucose level was measured every $30 \mathrm{~min}$. For the insulin tolerance test (ITT), the male mice fasted for $4-5 \mathrm{~h}$, and $1-1.2-\mathrm{U} / \mathrm{kg}$ insulin (Humulin, Lilly) was intraperitoneally introduced. For both GTT and ITT, the glucose level was measured immediately after collecting blood from the tail vein using an Accu Chek Performa glucometer (Roche, Basel, Switzerland).

\section{Plasma analysis}

The circulating insulin (Alpco, Salem, NH, USA) and IL1 $\beta$, IL18, and TNF $\alpha$ levels were assessed using ELISA according to the manufacturer's guidelines (R\&D Systems, Inc., Minneapolis, MN, USA).

Histology

Isolated tissues from mice were immediately fixed and embedded in paraffin. Sections $(5-\mu \mathrm{m}$ thick) were stained with hematoxylin. Eosin or immunohistochemical staining was performed following F4/80 antibody (Abcam, Cambridge, UK) incubation using the avidin-biotin complex method (Vector Laboratories, Burlingame, CA, USA).

\section{Sample preparation and protein analysis}

Immediately after dissection, the mouse tissues were quickly frozen in liquid nitrogen and kept at $-80^{\circ} \mathrm{C}$ until further processing. The tissue samples were ground in liquid nitrogen and lysed with RIPA buffer supplemented with a proteinase inhibitor (Roche) and phosphatase inhibitor. For immunoblotting analysis, antibodies for Atg7, p62, phospho-JNK, phospho-AKT (Thr308), phospho-AKT (Ser473) (Cell Signaling Technology, Danvers, MA, USA), JNK, caspase-1, heat shock protein 90 (Santa Cruz Biotechnology, Inc., Santa Cruz, CA, USA), and LC3 (Sigma) were used.

\section{RNA isolation and qRT-PCR}

Total RNA was extracted using the Tri-RNA reagent or RNA mini kit (Favorgen, Taiwan) according to the manufacturer's instructions, and 500 ng of total RNA was used for the first cDNA synthesis (Toyobo, Osaka, Japan). The synthesized cDNA was diluted 10-fold, and mRNA expression was quantified using qRT-PCR.

\section{ROS measurements}

The total cellular ROS level was analyzed using $2^{\prime}, 7^{\prime}$-dichlorofluorescein diacetate (DCF-DA) reagent. Briefly, the cells were treated with various drugs as indicated in the figures and replaced with 4- $\mu \mathrm{M}$ DCF-DA in PBS for 5-20 min. After washing with PBS, the ROS level was analyzed in terms of the fluorescence intensity at $485-\mathrm{nm}$ excitation and 530-nm emission wavelengths.

\section{Statistics}

Data is presented as the mean $\pm \mathrm{SEM}$, and statistical analysis was performed by unpaired Student's $t$-test using GraphPad Prism. In this study, $p<0.05, p<0.01$, $p<0.001$ represent $*, * *$, and $* * *$ respectively and were considered statistically significant.

\section{ACKNOWLEDGMENTS}

We thank Dr. Komatsu for Atg $7^{f / f l}$ mice, Seo-Eun Park for editing the manuscript, and Enago (http://www. enago.co.kr) for English language review.

\section{CONFLICTS OF INTEREST}

The authors declare that there is no conflict of interest associated with this manuscript. 


\section{GRANT SUPPORT}

This work was supported by a National Research Foundation of Korea (2014R1A2A1A11050599, 20080062286) and Korean Health Technology R\&D Project, Ministry of Health and Welfare, Republic of Korea (H13C1502)

\section{REFERENCES}

1. Ginsberg HN and Huang LS. The insulin resistance syndrome: impact on lipoprotein metabolism and atherothrombosis. Journal of cardiovascular risk. 2000; 7:325-331.

2. Weisberg SP, McCann D, Desai M, Rosenbaum M, Leibel RL and Ferrante AW Jr. Obesity is associated with macrophage accumulation in adipose tissue. The Journal of clinical investigation. 2003; 112:1796-1808.

3. Xu H, Barnes GT, Yang Q, Tan G, Yang D, Chou CJ, Sole J, Nichols A, Ross JS, Tartaglia LA and Chen H. Chronic inflammation in fat plays a crucial role in the development of obesity-related insulin resistance. The Journal of clinical investigation. 2003; 112:1821-1830.

4. Heilbronn LK and Campbell LV. Adipose tissue macrophages, low grade inflammation and insulin resistance in human obesity. Current pharmaceutical design. 2008; 14:1225-1230.

5. Wellen KE and Hotamisligil GS. Inflammation, stress, and diabetes. The Journal of clinical investigation. 2005; 115:1111-1119.

6. Schenk S, Saberi M and Olefsky JM. Insulin sensitivity: modulation by nutrients and inflammation. The Journal of clinical investigation. 2008; 118:2992-3002.

7. Olefsky JM and Glass CK. Macrophages, inflammation, and insulin resistance. Annual review of physiology. 2010; 72:219-246.

8. Anderson EJ, Lustig ME, Boyle KE, Woodlief TL, Kane DA, Lin C-T, Price JW, III, Kang L, Rabinovitch PS, Szeto HH, Houmard JA, Cortright RN, Wasserman DH and Neufer PD. Mitochondrial H2O2 emission and cellular redox state link excess fat intake to insulin resistance in both rodents and humans. The Journal of clinical investigation. 2009; 119:573-581.

9. Houstis N, Rosen ED and Lander ES. Reactive oxygen species have a causal role in multiple forms of insulin resistance. Nature. 2006; 440:944-948.

10. Furukawa S, Fujita T, Shimabukuro M, Iwaki M, Yamada Y, Nakajima Y, Nakayama O, Makishima M, Matsuda M and Shimomura I. Increased oxidative stress in obesity and its impact on metabolic syndrome. The Journal of clinical investigation. 2004; 114:1752-1761.

11. Wen H, Gris D, Lei Y, Jha S, Zhang L, Huang MT, Brickey WJ and Ting JP. Fatty acid-induced NLRP3-ASC inflammasome activation interferes with insulin signaling.
Nature immunology. 2011; 12:408-415.

12. Dostert C, Pétrilli V, Van Bruggen R, Steele C, Mossman BT and Tschopp J. Innate Immune Activation Through Nalp3 Inflammasome Sensing of Asbestos and Silica. Science. 2008; 320:674-677.

13. Cruz CM, Rinna A, Forman HJ, Ventura ALM, Persechini PM and Ojcius DM. ATP Activates a Reactive Oxygen Species-dependent Oxidative Stress Response and Secretion of Proinflammatory Cytokines in Macrophages. Journal of Biological Chemistry. 2007; 282:2871-2879.

14. Zhou R, Yazdi AS, Menu P and Tschopp J. A role for mitochondria in NLRP3 inflammasome activation. Nature. 2011; 469:221-225.

15. Nakahira K, Haspel JA, Rathinam VA, Lee SJ, Dolinay T, Lam HC, Englert JA, Rabinovitch M, Cernadas M, Kim HP, Fitzgerald KA, Ryter SW and Choi AM. Autophagy proteins regulate innate immune responses by inhibiting the release of mitochondrial DNA mediated by the NALP3 inflammasome. Nature immunology. 2011; 12:222-230.

16. Asano T, Ogihara $\mathrm{T}$, Katagiri H, Sakoda H, Ono H, Fujishiro M, Anai M, Kurihara H and Uchijima Y. Glucose transporter and $\mathrm{Na}+$ /glucose cotransporter as molecular targets of anti-diabetic drugs. Current medicinal chemistry. 2004; 11:2717-2724.

17. Castellano JM, Kim J, Stewart FR, Jiang H, DeMattos RB, Patterson BW, Fagan AM, Morris JC, Mawuenyega KG, Cruchaga C, Goate AM, Bales KR, Paul SM, Bateman RJ and Holtzman DM. Human apoE isoforms differentially regulate brain amyloid-beta peptide clearance. Science translational medicine. 2011; 3:89ra57.

18. Larsen CM, Faulenbach M, Vaag A, Volund A, Ehses JA, Seifert B, Mandrup-Poulsen T and Donath MY. Interleukin1 -receptor antagonist in type 2 diabetes mellitus. The New England journal of medicine. 2007; 356:1517-1526.

19. Herder C, Brunner EJ, Rathmann W, Strassburger K, Tabak AG, Schloot NC and Witte DR. Elevated levels of the antiinflammatory interleukin-1 receptor antagonist precede the onset of type 2 diabetes: the Whitehall II study. Diabetes care. 2009; 32:421-423.

20. Donath MY and Shoelson SE. Type 2 diabetes as an inflammatory disease. Nat Rev Immunol. 2011; 11:98-107.

21. Robertson RP, Harmon J, Tran PO and Poitout V. Beta-cell glucose toxicity, lipotoxicity, and chronic oxidative stress in type 2 diabetes. Diabetes. 2004; 53 Suppl 1:S119-124.

22. Masters SL, Dunne A, Subramanian SL, Hull RL, Tannahill GM, Sharp FA, Becker C, Franchi L, Yoshihara E, Chen Z, Mullooly N, Mielke LA, Harris J, Coll RC, Mills KH, Mok $\mathrm{KH}$, et al. Activation of the NLRP3 inflammasome by islet amyloid polypeptide provides a mechanism for enhanced IL-1beta in type 2 diabetes. Nature immunology. 2010; 11:897-904.

23. Kaushik S, Rodriguez-Navarro JA, Arias E, Kiffin R, Sahu S, Schwartz GJ, Cuervo AM and Singh R. Autophagy in hypothalamic AgRP neurons regulates food intake and 
energy balance. Cell metabolism. 2011; 14:173-183.

24. Quan W, Kim HK, Moon EY, Kim SS, Choi CS, Komatsu M, Jeong YT, Lee MK, Kim KW, Kim MS and Lee MS. Role of hypothalamic proopiomelanocortin neuron autophagy in the control of appetite and leptin response. Endocrinology. 2012; 153:1817-1826.

25. Yang CS, Kim JJ, Lee HM, Jin HS, Lee SH, Park JH, Kim SJ, Kim JM, Han YM, Lee MS, Kweon GR, Shong M and Jo EK. The AMPK-PPARGC1A pathway is required for antimicrobial host defense through activation of autophagy. Autophagy. 2014; 10:785-802.

26. Kim KH, Jeong YT, Oh H, Kim SH, Cho JM, Kim YN, Kim SS, Kim do H, Hur KY, Kim HK, Ko T, Han J, Kim HL, Kim J, Back SH, Komatsu M, et al. Autophagy deficiency leads to protection from obesity and insulin resistance by inducing Fgf21 as a mitokine. Nat Med. 2013; 19:83-92.

27. Fujitani $Y$, Kawamori $R$ and Watada $H$. The role of autophagy in pancreatic beta-cell and diabetes. Autophagy. 2009; 5:280-282.

28. Ebato C, Uchida T, Arakawa M, Komatsu M, Ueno T, Komiya K, Azuma K, Hirose T, Tanaka K, Kominami E, Kawamori R, Fujitani Y and Watada H. Autophagy is important in islet homeostasis and compensatory increase of beta cell mass in response to high-fat diet. Cell metabolism. 2008; 8:325-332.

29. Singh R, Xiang Y, Wang Y, Baikati K, Cuervo AM, Luu YK, Tang Y, Pessin JE, Schwartz GJ and Czaja MJ. Autophagy regulates adipose mass and differentiation in mice. The Journal of clinical investigation. 2009; 119:33293339 .

30. Kim J, Cheon H, Jeong YT, Quan W, Kim KH, Cho JM, Lim YM, Oh SH, Jin SM, Kim JH, Lee MK, Kim S, Komatsu M, Kang SW and Lee MS. Amyloidogenic peptide oligomer accumulation in autophagy-deficient beta cells induces diabetes. The Journal of clinical investigation. 2014; 124:3311-3324.

31. Yang L, Li P, Fu S, Calay ES and Hotamisligil GS. Defective hepatic autophagy in obesity promotes ER stress and causes insulin resistance. Cell metabolism. 2010; 11:467-478.

32. Cho MH, Cho K, Kang HJ, Jeon EY, Kim HS, Kwon HJ, Kim HM, Kim DH and Yoon SY. Autophagy in microglia degrades extracellular beta-amyloid fibrils and regulates the NLRP3 inflammasome. Autophagy. 2014; 10:1761-1775.

33. Wellen KE and Hotamisligil GS. Obesity-induced inflammatory changes in adipose tissue. The Journal of clinical investigation. 2003; 112:1785-1788.

34. Song $\mathrm{Y}$, Altarejos J, Goodarzi MO, Inoue H, Guo X, Berdeaux R, Kim JH, Goode J, Igata M, Paz JC, Hogan MF, Singh PK, Goebel N, Vera L, Miller N, Cui J, et al. CRTC3 links catecholamine signalling to energy balance. Nature. 2010; 468:933-939.

35. Igusa Y, Yamashina S, Izumi K, Inami Y, Fukada H, Komatsu M, Tanaka K, Ikejima K and Watanabe S. Loss of autophagy promotes murine acetaminophen hepatotoxicity. Journal of gastroenterology. 2012; 47:433-443.

36. Matsuzawa A and Ichijo H. Redox control of cell fate by MAP kinase: physiological roles of ASK1-MAP kinase pathway in stress signaling. Biochimica et biophysica acta. 2008; 1780:1325-1336.

37. Shi Y, Nikulenkov F, Zawacka-Pankau J, Li H, Gabdoulline R, Xu J, Eriksson S, Hedstrom E, Issaeva N, Kel A, Arner ES and Selivanova G. ROS-dependent activation of JNK converts p53 into an efficient inhibitor of oncogenes leading to robust apoptosis. Cell death and differentiation. 2014; 21:612-623.

38. Yousefi S, Perozzo R, Schmid I, Ziemiecki A, Schaffner T, Scapozza L, Brunner T and Simon HU. Calpain-mediated cleavage of Atg5 switches autophagy to apoptosis. Nature cell biology. 2006; 8:1124-1132.

39. Koga H, Kaushik S and Cuervo AM. Altered lipid content inhibits autophagic vesicular fusion. The FASEB Journal. 2010; 24:3052-3065.

40. Ouimet M. Autophagy in obesity and atherosclerosis: Interrelationships between cholesterol homeostasis, lipoprotein metabolism and autophagy in macrophages and other systems. Biochimica et Biophysica Acta. 2013; 1831:1124-1133.

41. Liao X, Sluimer JC, Wang Y, Subramanian M, Brown K, Pattison JS, Robbins J, Martinez J and Tabas I. Macrophage autophagy plays a protective role in advanced atherosclerosis. Cell metabolism. 2012; 15:545-553.

42. Liu K, Zhao E, Ilyas G, Lalazar G, Lin Y, Haseeb M, Tanaka KE and Czaja MJ. Impaired macrophage autophagy increases the immune response in obese mice by promoting proinflammatory macrophage polarization. Autophagy. 2015; 11:271-284.

43. Han MS, Jung DY, Morel C, Lakhani SA, Kim JK, Flavell RA and Davis RJ. JNK expression by macrophages promotes obesity-induced insulin resistance and inflammation. Science. 2013; 339:218-222.

44. Tschopp J and Schroder K. NLRP3 inflammasome activation: the convergence of multiple signalling pathways on ROS production? Nat Rev Immunol. 2010; 10:210-215.

45. Bruun JM, Stallknecht B, Helge JW and Richelsen B. Interleukin-18 in plasma and adipose tissue: effects of obesity, insulin resistance, and weight loss. European journal of endocrinology. 2007; 157:465-471.

46. Lagathu C, Yvan-Charvet L, Bastard JP, Maachi M, Quignard-Boulange A, Capeau J and Caron M. Long-term treatment with interleukin-1beta induces insulin resistance in murine and human adipocytes. Diabetologia. 2006; 49:2162-2173.

47. Sorbara MT and Girardin SE. Mitochondrial ROS fuel the inflammasome. Cell research. 2011; 21:558-560.

48. Wen H, Ting JPY and O'Neill LAJ. A role for the NLRP3 inflammasome in metabolic diseases[mdash]did Warburg miss inflammation[quest]. Nature immunology. 2012; 
13:352-357.

49. Vandanmagsar B, Youm Y-H, Ravussin A, Galgani JE, Stadler K, Mynatt RL, Ravussin E, Stephens JM and Dixit VD. The NLRP3 inflammasome instigates obesity-induced inflammation and insulin resistance. Nat Med. 2011; 17:179-188

50. Komatsu M, Waguri S, Chiba T, Murata S, Iwata J, Tanida I, Ueno T, Koike M, Uchiyama Y, Kominami E and Tanaka $\mathrm{K}$. Loss of autophagy in the central nervous system causes neurodegeneration in mice. Nature. 2006; 441:880-884.
51. Cho HM, Kang YH, Yoo H, Yoon SY, Kang SW, Chang EJ and Song Y. Panax red ginseng extract regulates energy expenditures by modulating PKA dependent lipid mobilization in adipose tissue. Biochemical and biophysical research communications. 2014; 447:644-648. 